\title{
FIXED POINTS BY MEAN VALUE ITERATIONS
}

\author{
GORDON G. JOHNSON
}

AbSTRaCt. If $E$ is a convex compact subset of a Hilbert space, $T$ is a strictly pseudocontractive function from $E$ into $E$ and $x_{1}$ is a point in $E$, then the point sequence $\left\{x_{i}\right\}_{i=1}^{\infty}$ converges to a fixed point of $T$, where for each positive integer $n$,

$$
x_{n+1}=[1 /(n+1)]\left[T x_{n}+n x_{n}\right] .
$$

In this paper it is shown that a technique of W. R. Mann [1] is fruitful in finding a fixed point of a function even though a "Picard" iteration may fail. The technique of Mann is similar to some of the techniques used in [2].

THEOREM. If $E$ is a compact convex subset of a Hilbert space $H, T$ is a strictly pseudocontractive function from $E$ into $E$ and $x_{1}$ is any point in $E$, then the point sequence $\left\{x_{i}\right\}_{i=1}^{\infty}$ converges in the norm of $H$ to a fixed point of $T$, where for each positive integer $n, x_{n+1}=[1 /(n+1)]\left[T x_{n}+n x_{n}\right]$.

Proof. By a well-known result of Schauder [3], $T$ has a fixed point in $E$. Let $p$ denote one such fixed point of $T$ and $x_{1}$ a point in $E$. Since $H$ is a Hilbert space, it is easily shown that for each positive integer $n$,

$$
\begin{aligned}
\left\|x_{n+1}-p\right\|^{2}= & {[1 /(n+1)]\left\|T x_{n}-p\right\|^{2} } \\
& +[n /(n+1)]\left\|x_{n}-p\right\|^{2}-\left[n /(n+1)^{2}\right]\left\|T x_{n}-x_{n}\right\|^{2}
\end{aligned}
$$

where $x_{n+1}=[1 /(n+1)]\left[T x_{n}+n x_{n}\right]$.

Since $T$ is strictly pseudocontractive, there is a number $k, 0 \leqq k<1$, such that if each of $x$ and $y$ is in $E$ then

$$
\|T x-T y\|^{2} \leqq\|x-y\|^{2}+k\|(I-T) x-(I-T) y\|^{2} .
$$

Hence

$$
\begin{aligned}
\left\|T x_{n}-p\right\|^{2} & \leqq\left\|x_{n}-p\right\|^{2}+k\left\|x_{n}-T x_{n}\right\|^{2}, \\
\left\|x_{n+1}-p\right\|^{2} & \leqq\left\|x_{n}-p\right\|^{2}-\left[[n-k(n+1)] /(n+1)^{2}\right]\left\|T x_{n}-x_{n}\right\|^{2} .
\end{aligned}
$$

Received by the editors November 22, 1971.

AMS 1970 subject classifications. Primary 47A85; Secondary 40A32.

(c) American Mathematical Society 1972 
There is a positive integer $N$ such that $N /(N+1)>k$ and therefore if $j$ is a positive integer

$$
\begin{aligned}
\left\|x_{N+j}-p\right\|^{2} & \leqq\left\|x_{N+j-1}-p\right\|^{2} \\
& -\left[[(1-k)(N+j-1)-k] /(N+j)^{2}\right]\left\|T x_{N+j-1}-x_{N+j-1}\right\|^{2}
\end{aligned}
$$

from which it follows that

$$
\begin{aligned}
& \left\|x_{N+j+1}-p\right\|^{2} \\
& \quad \leqq\left\|x_{N}-p\right\|^{2}-\sum_{t=0}^{j}\left[[(1-k)(N+t)-k] /(N+t+1)^{2}\right]\left\|T x_{N+t}-x_{N+t}\right\|^{2} .
\end{aligned}
$$

Since $E$ is bounded the above implies that

$$
\sum_{t=0}^{\infty}\left[[(1-k)(N+t)-k] /(N+t+1)^{2}\right]\left\|T x_{N+t}-x_{N+t}\right\|^{2}<\infty
$$

and $\left\|x_{N+j+1}-p\right\| \leqq\left\|x_{N+j}-p\right\|$ for $j=1,2, \cdots$.

Hence

$$
\lim _{t \rightarrow \infty}\left\|T x_{N+t}-x_{N+t}\right\|=0 .
$$

Since $E$ is compact there is a subsequence $\left\{x_{N+n_{i}}\right\}_{i=1}^{\infty}$ which converges to a point $q$ in $E$. Notice that $q$ is a fixed point of $T$.

Since $q$ is a fixed point of $T$ we have for each positive integer $j$ that

$$
\left\|x_{N+j+1}-q\right\| \leqq\left\|x_{N+j}-q\right\| \text {. }
$$

This last comment combined with the fact that $\left\{x_{N+n_{i}}\right\}_{i=1}^{\infty}$ converges to $q$ yields the desired result, namely that $\left\{x_{i}\right\}_{i=1}^{\infty}$ converges to $q$, which is a fixed point of $T$.

\section{REFERENCES}

1. W. R. Mann, Mean value methods in iteration, Proc. Amer. Math. Soc. 4 (1953), 506-510. MR 14, 988.

2. F. E. Browder and W. V. Petryshyn, Construction of fixed points of nonlinear mappings in Hilbert spaces, J. Math. Anal. Appl. 20 (1967), 197-228. MR 36 \#747.

3. J. Schauder, Der fixpunktsatz in funktionalraumen, Studia Math. 2 (1970), 171-180.

4. R. L. Franks and R. P. Marzec, A theorem on mean value iterations, Proc. Amer. Math. Soc. 30 (1971), 324-326.

Department of Mathematics, University of Houston, Houston, Texas 77004 